\title{
TUNDEKAUSATIIVIKONSTRUKTSIOON EESTI MOODI
}

\author{
LIINA LINDSTRÖM
}

\section{Sissejuhatus}

$\mathrm{K}$ ogemissündmust väljendavates konstruktsioonides on tüüpiliselt kaks osalist: kogeja (K), kelle sisemist seisundit mingi väline tegur mõjutab, Olulisem on kahtlemata kogeja ise, kes tajub, tunneb ja mõtleb, poonjustab. Olulisem on kahtlemata kogeja ise, kes tajub, tunneb ja mõtleb, stiimulit ei pruugi aga alati olla üldse olemas või pole see oluline: näiteks lauses $M u l$ on igav on olemas küll kogeja (mina), ent mitte stiimulit, mis seda seisundit kuidagi põhjustaks. Reeglina ongi kogemissündmuses kogeja prominentsem osaleja kui stiimul (Bickel 2004: 77) ja seda ilmselt seetõttu, et tüüpiline kogeja on inimene.

Kogejat sisaldavatel lausetel on võrreldes muude lausetüüpidega paljudes keeltes mitmesuguseid eripärasid. Eelkõige puudutab see kogeja ja stiimuli lauses märkimist, mis võib olla väga varieeruv. Tavaliselt räägitakse kolmest peamisest kogeja markeerimise tüübist (Bossong 1998; Haspelmath 2001), kõik need kolm tüüpi on ka eesti keeles esindatud:

1. Kogeja markeeritakse nagu agent (s.t nagu transitiivse lause subjekt), stiimul nagu patsient (objektina):

(1) $M a(\mathrm{~K})$ armastan muusikat (St).

2. Kogeja markeeritakse daativiga (eesti keeles vastab sellele adessiiv või allatiiv) ja stiimul on markeeritud nagu intransitiivse lause subjekt: ta on nominatiivis ja ühildub verbiga:

(2) Annile (K) meeldivad banaanid (St).

3. Kogeja on markeeritud nagu patsient (s.t objektina) ja stiimul nagu agent (s.t subjektina):

\section{(3) Mind (K) hirmutavad teie mõtted (St).}

Nende kolme tüübi olemasolu on motiveerinud tõenäoliselt kogemissündmuse semantiline komplekssus, kausaalne kahesuunalisus: ühelt poolt peab kogeja suunama oma tähelepanu stiimulile, teiselt poolt mõjutab stiimul kogejat ja tekitab temas mingi seisundi (Croft 1993: 64). Samuti mõjutab seda kahtlemata kogeja roll sündmuses: mil määral kogeja olukorda kontrollib.

Käesoleva artikli huviobjektiks on kolmas tüüp, mida kasutatakse seetõttu, et stiimul põhjustab kogejas mingi mentaalse seisundi, mida kogeja ei suuda kontrollida. 
Martin Haspelmathi väitel on Euroopa standardsele keskmisele (SAE) keelele iseloomulik pigem 1. tüüp, 2. ja 3. tüüp on iseloomulikud pigem mitte SAE-keelele (Haspelmath 2001: 63), sh ka eesti keelele (Bossong 1998).

Eesti keeles on levinud kõik kolm konstruktsioonitüüpi, neist 2. ja 3. on grammatikakäsitlustes ühendatud mõiste kogejalause alla: neid ühendab pööratud sõnajärg (XVS) ja kogeja markeerimine teisiti kui grammatilise subjektina, samal ajal kui 1. tüüp on normaallause sõnajärjega (SVX), milles kogeja on grammatiline subjekt (EKK; Erelt, Metslang 2006; 2008).

Senistes uurimustes (Metslang 2006; 2007; Erelt, Metslang 2008) on välja toodud tendents, et kui teatavat kogemissündmust saab väljendada mitmel viisil, kaldutakse ka eesti keeles eelistama normaallausekujulist (1. tüüpi) kogejakonstruktsiooni: vähemalt ajaperioodi 1995-2005 korpuse andmete põhjal on märgatud mõningast nominatiivse (1. tüüpi) kogeja sagenemist. Nii eelistatakse näiteks lauset 5, milles kogeja on markeeritud subjektina, lausele 4, kus kogeja on objekt (Metslang 2006; 2007; Erelt, Metslang 2008).

(4) Võit rõõmustas Annat.

(5) Anna rõ̃omustas võidu üle.

Artiklis käsitletakse 3. tüüpi kogejakonstruktsiooni, milles kogeja on markeeritud nagu grammatiline objekt ja stiimul nagu grammatiline subjekt. Konstruktsioon väljendab sündmust, milles elutu stiimul mõjutab elusat kogejat ning tekitab temas mingi tundeseisundi. Konstruktsiooni keskmeks on (enamasti) kausatiivse sufiksiga verbid. Seetõttu nimetan konstruktsiooni edaspidi tundekausatiivikonstruktsiooniks (TKK), nagu on tehtud ka soome keeleteaduses (vt nt Siiroinen 2001; ISK). Ivi Toluki bakalaureusetöö (2002) põhjal on eesti keeles vähemalt 55 verbi, mis selles konstruktsioonis osalevad, neist 44 on kausatiivse sufiksiga $-t a$ -

Artikli esimeses osas vaatlen konstruktsiooni muude läänemeresoome keelte ja indoeuroopa naaberkeelte taustal, et välja selgitada muutusi, mis eesti keeles toimunud on. Artikli teises osas võrdlen tundekausatiivikonstruktsiooni agentiivse konstruktsiooniga, mis moodustatakse osalt samade predikaatidega, ent milles stiimul on agentiivne, s.t teadlikult ja tahtlikult toimiv isik. TKK ja agentiivse konstruktsiooni võrdlus aitab välja selgitada neid omadusi, mis on ainuomased TKK-le ning mis on tingitud peamiselt subjekti ja objekti ebatüüpilisusest.

\section{Tundekausatiivikonstruktsioon läänemeresoome keeltes}

Eesti keelega sarnane tundekausatiivikonstruktsioon, milles kogeja on markeeritud nagu objekt, on iseloomulik kõigile läänemeresoome keeltele. Erinevused seisnevad peamiselt stiimuli olemasolus: soome, vepsa ja vadja keeles võib TKK esineda ka stiimulita, ilma et konstruktsioon mõjuks elliptiliselt (võrdle näiteid 6 ja 7 soome keele kohta, 8 ja 9 vadja keele kohta).

(6) soome

Mattia pelottaa.

'Matit hirmutab' 
(7) soome

Mattia pelottaa työ. (Pörn 2008: 202)

'Matit hirmutab töö'

(8) vadja

minua aikutaB, vähä makazin (Heinsoo 2010: 29)

'Mind ajab haigutama, vähe magasin'

(9) vadja

kase sü̈tši minua inotaB (Heinsoo 2010: 32)

'see söök on mulle vastik'

Seega võib neis läänemeresoome keeltes TKK esineda nii stiimuliga kui ka ilma. Vaid vepsa keele puhul pole siinkirjutajal päris selge, kas konstruktsioon võib esineda ka koos nimetavas käändes stiimuliga: Maria Zaitseva vepsa lauseõpetusest (2001) ei leidnud ma selle kohta ühtegi näidet. Tõenäoliselt on stiimuli lisamine vepsa keeles siiski võimalik.

(10) vepsa

mindei säreidiitab (Zaitseva 2001: 81)

'mul on jahe'

Eesti keeles seevastu on stiimul lausestruktuuris kohustuslik argument, seda ei saa lausest välja jätta: laused Mind hirmutab, Mind ehmatas mõjuvad poolikult ja ebagrammatiliselt. Vaid verbiga ängistama leidsin korpustest näite 11, kus lauses stiimulit pole ning lause mõjub grammatiliselt terviklikult. ${ }^{1}$ Tundub siiski, et keelekasutaja on hakanud ka selle verbiga eelistama 2. tüüpi kogejakonstruktsiooni, milles kogeja on markeeritud alalütleva käändega (näide 12): võimalik, et just seetõttu, et ilma stiimulita TKK mõjub poolikult.

(11) Sind ei ängista, Bronka?

(12) Tead, kõik, kõik on justkui kodus korras, aga ma kardan, mul ängistab, ma kardan ja kahtlustan kõike ja kõiki.

Siiski on analüütilise kausatiivse verbiga ajama võimalik TKK moodustada ilma stiimulita, nt mind ajab köhima, mind ajab vihale. (Sama on täheldanud ka Erelt, Metslang 2006.)

Mõningaid näiteid võib stiimulita TKK kasutamise kohta leida ka kirderannikumurdest, millel on süntaktilisi ühisjooni ida- ja lounaeesti murretega ning põhja- ja idapoolsemate läänemeresoome keeltega (Must 1987: 284). Näited 13-14 on aga huvitavad selle poolest, et kogejana ei ole siin vormistatud elus osaline, vaid ta kehaosa (ja nii oli see kõigis Mari Musta vastavates näidetes); elus osaline (ehk tegelik kogeja) on näites 14 lisatud adessiivse argumendina, mida on võimalik tõlgendada omajana. Kas on tegemist näidete juhuslikkuse või mingit sorti üleminekukonstruktsiooniga, pole selge.

1 Sama on väitnud ka Tiia Palosaar (isiklik teade). 
(13) pöät aiGetta (VNg), pö́a kivistä (Vai)

'pea valutab' (Must 1987: 288)

(14) mul aikettapki setä kontti (Lüg)

'mul valutab see kont' (Must 1987: 288)

Kahtlemata on ka muudes läänemeresoome keeltes piiranguid, milliste verbidega stiimul lauses on vajalik, millistega mitte. Eesti keeles on aga stiimul - väheste eranditega - muutunud lause obligatoorseks osaks.

Eesti keel ei ole siiski ainus läänemeresoome keel, kus TKK-s on stiimul muutunud konstruktsiooni obligatoorseks osaks: ka liivi keeles on stiimul kinnistunud konstruktsiooni (näide 15). ${ }^{2}$

(15) liivi

Se kõzātiz tī̄nda.

'See pahandas teda' (Viitso, käsikiri)

Nii eesti kui ka liivi keelel on teatavasti olnud pikaajalised kontaktid läti keelega. Üks võimalikke mõjuallikaid võib seega olla läti keel, milles samuti on stiimul lauses obligatoorne (näide 16). ${ }^{3}$ Analoogiliselt kasutatakse aga TKK-d ka vene keeles (näide 17), millel on samuti pikaajalised kontaktid eesti keelega. Vene keeles on siiski üksikute verbidega võimalik ka ilma stiimulita tundekausatiivikonstruktsioon (näide 18). ${ }^{4}$ Kas selle taga on omakorda läänemeresoome keelte mõju, pole selge. Stiimuli kinnistumisel lausestruktuuri ei saa välistada loomulikult ka saksa keele mõju. Seetõttu on võimalik, et siin ei ole otseselt või ainult läti või vene keele mõju, vaid tegemist on laiema indoeuroopa keelte mõjuga.

(16) $\operatorname{läti}^{5}$

Visvairāk mani interesē manu bērnu nākotne.

Kõige_rohkem mina:ACC huvitama:SG3 mina:PL:GEN laps:PL:GEN tulevik

'Mind huvitab kõige rohkem oma laste tulevik'

(17) vene

Меня больше всего интересует будущее моих детей.

Mina:ACC rohkem kõik:GEN huvitama:SG3 tulevik mina-PL:GEN laps:PL:GEN

'Mind huvitab kõige rohkem oma laste tulevik'

(18) vene

Меня тошнит.

mina-ACC oksele_ajama:SG3

'Mind ajab oksele'

Stiimuli kinnistumisega lausestruktuuri on TKK muutunud eesti keeles väliselt sarnaseks transitiivse normaallausega, peamiseks erinevuseks on semantilised rollid ning OVS-sõnajärg (normaallause sõnajärg on SVO). Eri-

\footnotetext{
2 Valt Ernštreiti suuline teade.

3 Ilze Zagorska suuline teade.

${ }^{4}$ Renate Pajusalu suuline teade.

5 Tänan läti, liivi ja vene keele andmete eest Jana Šteinberga-Rankit, Valt Ernštreiti, Tuuli Tuisku ja Olga Gerassimenkot.
} 
nevusi võib siiski leida konstruktsioonide käitumises. Ühelt poolt on need seotud objekti ebatüüpilisusega (objekt viitab inimesele, paikneb lause alguses), teiselt poolt subjekti ebatüüpilisusega (ei viita TKK-s inimesele, paikneb lause lõpus).

\section{Kogeja subjekti omadused}

Kogeja on semantiline roll, mis eeldab elusat inimesest osalist: osalist, kes on võimeline tundma või kellega inimene (kõneleja) on võimeline ennast samastama. Tüüpiliselt valitakse kogeja lauses empaatiahierarhia (elusushierarhia) algusest (küll väikeste variatsioonidega, aga enamasti kujutatakse empaatiahierarhiat nii: $1 .>2$. $>3$. isiku pronoomen $>$ pärisnimi $>$ inimene $>$ elusolend $>$ elutu olend, vt nt Palmer 1994: 30). Sama on iseloomulik ka tüüpilisele (kanoonilisele) subjektile (vt nt Andrews 1985). Eesti keelele on üldiselt omane SV-sõnajärg: tuntud referendile viitav (nt asesõnaline) subjekt paikneb reeglina enne verbi, v.a V2-reeglist tingitud inversiooni puhul (vt nt Lindström 2002; EKK; Tael 1988). Seega on objektina markeeritud kogejal mitmesuguseid subjekti omadusi.

Lisaks eespool mainitud omadustele on tüüpilisel subjektil käitumisomadusi, mida teistel lauseliikmetel ei ole või esineb piiratult (vt nt ülevaateid Keenan 1976; Andrews 1985; Onishi 2001; Barðdal 2006). Subjekti käitumisomadused võivad avalduda ka muudel lauseliikmetel (näiteks adverbiaalidel), kui nad on hakanud subjektitaoliseks grammatiseeruma: neile on tekkinud subjekti käitumisomadused, ent subjekti vormistusomadusi (nimetavat käänet, verbiga ühildumist) veel ei ole, need võivad lisanduda grammatisatsiooniprotsessi mõnes hilisemas etapis (Givón 1997; Haspelmath 2010). Mati Erelt (2004) on eesti subjektile iseloomulike käitumisomadustena nimetanud refleksiivpronoomeni kasutamise kontrolli, rindliikme kustutust, imperatiivi moodustust, samasuskustutust ning subjektiks või objektiks tõstet. Järgnevalt vaatlen lähemalt, millised subjekti omadused on objektina markeeritud kogeja tundekausatiivikonstruktsioonis omandanud.

\subsection{Refleksivatsioon}

Subjekt kontrollib tüüpiliselt refleksiivpronoomeni oma või enda kasutamist, nt Peeter jutustas kallimale iseendast / oma elust (vt Erelt 2004: 9).

TKK kogeja (mis on markeeritud nagu objekt) kontrollib samuti refleksiivpronoomeni kasutamist, s.t refleksiivpronoomen oma või enda viitab kogejast objektile (mind) (näited 19-20). Refleksivatsiooni kontrollijana toimib objekt ka soome keeles TKK-s (näide 21), aga mitte näiteks läti (näide 22) ega vene keeles (näide 23), kus samas positsioonis tuleb korrata isikulist asesõna ('mina').

(19) Mind hirmutab kõige rohkem oma laste tulevik.

(20) Mind ehmatas enda nägemine peeglist.

(21) soome

Reinoa hävetti oma käytöksensä. (Siiroinen 2001: 52)

'Reino häbeneb oma käitumist' 
(22) läti

Visvairāk mani biedē manu bērnu nākotne.

kõige rohkem mina:ACC hirmutama:SG3 mina:GEN laps:PL:GEN tulevik 'kõige rohkem hirmutab mind oma laste tulevik'

(23) vene

Меня больще всего пугает будущее моих детей.

mina:ACC rohkem kõik:GEN hirmutama:SG3 tulevik mina:PL:GEN laps:PL:GEN

'kõige rohkem hirmutab mind oma laste tulevik'

\subsection{Rindliikme kustutus}

Teine oluline subjekti omadus on kontrollida samaviitelise subjekti kustutust teises rinnastatud osalauses, nt Tüdrukud piilusid poisse ja _ [tüdrukud] itsistasid (Erelt 2004).

Objektina markeeritud kogejal eesti keeles seda omadust ei ole, vähemalt mitte siis, kui ühes osalauses on n-ö kanooniline subjekt, teises TKK-sse kuuluv objekt (näide 24). Rindliikme kustutus on võimalik vaid sel juhul, kui mõlemas rinnastatud lauseosas on tegemist TKK-sse kuuluva samaviitelise objektiga (näide 25). Siiski ei ole see enam subjektile iseloomulik omadus, mis lauses 25 avaldub: kui tegemist on samas vormis ja samas grammatilises funktsioonis oleva noomenifraasiga, siis on selline väljajätt võimalik ka muude lauseliikmetega, mitte ainult subjektiga (vt nt Koks 2004).

(24) *Te-da hirmuta-s mu väljanägemine ja _ jooksi-s koju.

(25) Teda hirmutas mu väljanägemine ja _ üllatas mu äkilisus.

Ka soome keele puhul on väidetud, et rindliikme kustutus TKK-s pole võimalik nii, et seda kontrolliks kogeja (Sands, Campbell 2001: 255), ent Mari Siiroinen (2001: 52) on siiski korpusest leidnud ühe lause, kus see toimib (näide 26), ja selle põhjal on ta seisukohal, et soome keeles see subjektilisuse test siiski osutab kogeja subjektitaolisusele.

(26) Marista erottua asteli hän hiljalleen kotia päin, mieli maan tasalla ja _ pelotti. (Siiroinen 2001: 52)

Eesti keele puhul rindliikme kustutuse test aga TKK kogeja subjektitaolisusele ei osuta.

\subsection{Samasuskustutus}

Samasuskustutus on subjekti omaduseks peetav nähtus, kus pealause subjekt kontrollib lisatavas infiniitkonstruktsioonis samaviitelise argumendi kustutust, nt Ma tahan _ [ma] suppi keeta. Meid huvitab, kas objekt (kogeja) saab kontrollida samasuskustutust tundekausatiivikonstruktsioonis, s.t kas tundekausatiivikonstruktsiooniga saab kasutada infiniitkonstruktsiooni, mis eeldab samaviitelisust TKK kogejaga (näites 27 teid huvitab - teie kuulete).

(27) Vahest huvitab teid seda kuulda. 
See test toimib hästi nii soome (näide 28), vepsa (näited 29-30) kui ka vadja (näide 31) keele puhul, s.t neis keeltes on kogejal (= objektil) see subjekti omadus olemas.

(28) soome

Reinoa hävetti pyytää lainaa. (Siiroinen 2001: 53)

Reino:PRT häbenema:PST:SG3 paluda-INF laen-PRT

'Reino häbenes laenu küsida'

(29) vepsa

händast himoitab kargeita (Zaitseva 2001: 108)

'ta tahab tantsida'

(30) vepsa

tatad himoitab ostta uuz' veneh (Zaitseva 2001: 110)

isa:PRT soovima:SG3 ostma:INF uus paat

'isal on soov osta uus paat'

(31) vadja

minua inotti süvvä sitä sü̈šiä (Heinsoo 2010: 96)

mina:PRT vastik_olema:PST:SG3 sööma:INF see:PRT söök:PRT

'mul on vastik seda sööki süüa'

Eesti keele puhul toimib see test aga väga piiratult: laused, kus infiniitkonstruktsioon TKK subjektina esineb (s.t kus samasuskustutus toimib), on paljudele keelekasutajaist vastuvõetamatud või raskesti aktsepteeritavad (näited 32-33). 1990. aastate ilukirjanduskorpusest (http://www.cl.ut.ee/korpused/segakorpus / eesti_ilukirjandus_1990/) võis siiski leida kuus huvitamaverbiga lauset, kus samasuskustutus toimib (näited 34-35).

(32) ?Mind rusus üksi kodus olla.

(33) ?Reinu hirmutas küsida laenu.

(34) Keda huvitaks mind viis aastat oodata?

(35) Vahest huvitab teid kuulda, mis teie siiajäänud varandusest on saanud.

Samasuskustutus ei toimi ka läti ega vene keeles, seetõttu võib siin oletada taas indoeuroopa keelte mõju.

Seega näeme, et läänemeresoome keeltes on TKK kogejal mitu subjekti omadust: ta viitab inimesele, paikneb lause algul, kontrollib refleksivatsiooni (seda vähemalt soome ja eesti keeles) ja kontrollib samasuskustutust. Rindliikme kustutus võib mingil määral toimida soome keeles (Siiroinenil üks näide), ent reeglina see läänemeresoome keeltes ei toimi, vähemalt mitte siis, kui teises rindlauses on nominatiivne samaviiteline subjekt.

Eesti keel on võrreldes teiste läänemeresoome keeltega kaotanud TKK-le iseloomulikke jooni: lisaks stiimuli obligatoorseks muutumisele on vähenenud ka kogeja subjektitaolised omadused, hästi toimib vaid refleksivatsiooni test. Tõenäoliselt on kogeja subjekti omaduste vähenemine seotud stiimuli kinnistumisega konstruktsiooni: et konstruktsioon on välispidiselt sarnastunud tavalise transitiivse lausega, siis on see kaasa toonud ka argumentide käitu- 
misomaduste sarnastumise: subjektile iseloomulikud käitumisomadused ei avaldu enam kogejast objektil. Teisisõnu, stiimuli lausesse kinnistumine on peatanud kogeja subjektiks grammatiseerumise, mille üheks etapiks on peetud subjekti käitumisomaduste avaldumist mittesubjektist argumendil (vt Givón 1997; Haspelmath 2010).

Seega on eesti keel muutunud sarnasemaks läti ja vene keelega, milles samuti on stiimul lauses obligatoorne argument ja milles TKK kogejal ei ole selliseid subjekti omadusi nagu enamikus läänemeresoome keeltes.

\section{Stiimuli agentiivsus ja mitteagentiivsus ning sellega seotud süntaktilised piirangud}

Stiimuli TKK-sse kinnistumine toob kaasa olukorra, kus lause sarnaneb pealtnäha tavalise transitiivse lausega, ent peamine erinevus seisneb grammatiliste ja semantiliste rollide vahekorras. TKK-s on objektiks tüüpiliselt elus kogeja, subjektiks elutu stiimul (näide 36); transitiivses lauses on tüüpiliselt (prototüüpselt) tegu aga elus agendiga subjekti rollis ning elus või elutu patsiendiga objekti rollis. Paljude TKK predikaatidega saab aga moodustada ka konstruktsiooni, mis sarnaneb pigem tüüpilise transitiivse konstruktsiooniga: see on agenditaolise stiimuliga konstruktsioon (edaspidi: agentiivne konstruktsioon; vt näidet 37). Agentiivne konstruktsioon võib tüüpilise tundekausatiivikonstruktsiooniga paralleelselt eksisteerida, ent neil kahel konstruktsioonitüübil on süstemaatilisi erinevusi, mis avalduvad piirangutena süntaktilistes protsessides (vt näiteks ka Verhoeven 2010). Et enamik neist piirangutest on seotud grammatilise subjekti (stiimuli) agentiivsuse ja subjekti omadustega, siis võib öelda, et taas on tegu subjekti ebatüüpilisusest tingitud nähtustega.

Nagu öeldud, eristab agentiivset konstruktsiooni tundekausatiivikonstruktsioonist eelkõige stiimuli agentiivsus: stiimuliks on teadlikult ja tahtlikult toimiv elus osaline (vrd näiteid 36 ja 37 ).



Mind hirmutas tema väljanägemine. kogeja stiimul objekt subjekt

Naabrionu hirmutas last vitsakimbuga. stiimul/agent kogeja/patsient subjekt objekt

Alati pole stiimuli agentiivsus siiski päris selge, näiteks lauses 38 viitab stiimul küll elusale osalisele, ent pole selge, kas ta käitub teadlikult ja tahtlikult. Siin aitab meid ühelt poolt kontekst (lauses 38 osutab järelduslik ju, et ilmselt mina-isik ei tegutsenud tahtlikult), teiselt poolt võime testina kasutada tahtlikkusele osutavat määrust meelega: kui lausesse saab lisada meele$g a$, siis on tegemist pigem agentiivse konstruktsiooniga (vt ka Verhoeven 2010).

(38) Ju ma polnud Aolille esimesel ööl ära hirmutanud. 
Järgnevalt võrdlen omavahel agentiivset ja (mitteagentiivset) tundekausatiivikonstruktsiooni sisaldavaid lauseid, mis on pärit TÜ 1990. aastate ilukirjanduskorpusest (http://www.cl.ut.ee / korpused/segakorpus / eesti_ilukirjandus_1990/). Eesmärk on leida need piirangud, mis tundekausatiivikonstruktsioonil on võrreldes agentiivse konstruktsiooniga. Võrdlen predikaate, mis võivad mooodustada ainult tundekausatiivikonstruktsiooni (huvitama, hämmastama, vaimustama, ängistama, rusuma, heidutama, kohutama), nendega, mis võivad moodustada nii agentiivset konstruktsiooni kui ka TKK-d (hirmutama, ehmatama, üllatama, ärritama, häirima).

\subsection{Impersonaali kasutamine}

Agentiivne konstruktsioon ja TKK käituvad erinevalt nii impersonaliseerimise kui ka passiveerimise käigus, olulisemad erinevused tulevad esile eelkõige impersonaliseerimisel: TKK-st reeglina impersonaalset lauset moodustada ei saa. Teatavasti kustutatakse impersonaali moodustamisel lähtelause subjekt ning predikaat pannakse umbisikulisse tegumoodi. Seejuures saab impersonaali kasutada vaid siis, kui lähtelause subjekt viitab inimesele (Rajandi 1999; Pihlak 1993). See on ühtlasi põhjus, miks TKK-st ei saa impersonaalset konstruktsiooni moodustada: TKK stiimul on tüüpiliselt elutu. Tegemist ei ole aga ainult stiimuli elutusega, vaid siiski kogu konstruktsiooni omadusega - sellele viitab asjaolu, et see piirang laieneb ka neile juhtumitele, kus lähtelause subjekt (stiimul) viitab inimesele (kes aga ei tegutse teadlikult või tahtlikult nagu tüüpiline agent, vt näiteid 39-40).

(39) Ethel huvitab mind. *Mind huvitatakse.

(40) Vanad sõbrad hämmastasid mind eile. *Mind hämmastati eile.

Sama piirang laieneb muide ka datiivsetele kogejakonstruktsioonidele, milles samuti stiimul on grammatiline subjekt ning tüüpiliselt elutu (näide 41).

(41) Need inimesed meeldivad mulle. *Mulle meelditakse.

Agentiivse konstruktsiooniga on aga impersonaali võimalik moodustada ilma piiranguteta (näited 42-43).

(42) Kui rahvas muidu ei kuuletu, siis ta lihtsalt hirmutatakse surmani ära.

(43) Kui ma vihastan või mind ehmatatakse, võib mõnikord midagi iseenesest põlema minna, ma ei peagi selle peale mõtlema.

Seega puudutab piirang vaid tundekausatiivikonstruktsiooni. Kui predikaat võib moodustada nii agentiivse konstruktsiooni kui ka TKK, siis esindab impersonaalne lause agentiivset konstruktsiooni. See seletab, miks näide 40 võib teatavates kontekstides olla siiski vastuvõetav.

\subsection{Passiiv}

Impersonaaliga seotud piirangud ei puuduta aga kuidagi passiivi: nii agentiivse konstruktsiooni kui ka TKK-ga saab passiivi vabalt moodustada. Passiveerimise käigus ülendatakse objekt lause subjektiks ning olema-verb ühil- 
dub sellega arvus ja isikus. Agentiivse ja TKK erinevused ilmnevad aga stiimuli markeerimises (juhul kui seda üldse lauses väljendatakse).

Passiivilauses väljendatakse agenti (s.t osalist, mis vastavas aktiivilauses on subjekt) suhteliselt harva, ent selleks on mitu erinevat võimalust (vt nt Rajandi 1999; Pihlak 1993): poolt-konstruktsioon, adessiiv, elatiiv, genitiiv. Kirjalikus keeles on kõige tavalisem poolt-konstruktsioon (Torn 2006), suulises markeeritakse agenti pigem adessiiviga (Lindström, Tragel 2007). Elutut agenti markeeritakse reeglina elatiiviga (Rajandi 1999; Uuspõld 1970), adessiivi ei saa aga elutu agendi puhul üldse kasutada. Süntaktiliselt kõige seotum on genitiiv, mis võib esineda vaid $t u d$-partitsiibi seotud laiendina (vt Sahkai 2011).

Tundekausatiivikonstruktsiooni passiveerimisel kasutatakse stiimuli (lähtelause subjekti) väljendamiseks peaasjalikult elatiivi (näide 44), ja seda ka siis, kui stiimul viitab inimesele (näited 45-46). Adessiivi ega pooltkonstruktsiooni kasutamine ei tule TKK puhul kõne alla (näide 47).

(44) Mõni loob suuri luulelugusid kokku ja seltskond on ta lorast vaimustatud.

(45) Kui oled vaimustatud inimesest, on sulle ka jumalad inimeste sarnased.

(46) Viieteistkümnesele on see traagika: keegi ei märka mind, keegi pole minust huvitatud, ma ei lähe kellelegi korda.

(47) *Kui oled inimese poolt vaimustatud / inimesel vaimustatud...

Põhjuseks võib olla ühelt poolt TKK tüüpilise stiimuli elutus, teiselt poolt aga asjaolu, et stiimulit markeeritakse elatiiviga ka muudes tundeseisundeid väljendavates konstruktsioonides (näide 48).

(48) Mul on sinust kahju.

Agentiivse konstruktsiooni passiveerimisel kasutatakse aga peaasjalikult poolt-konstruktsiooni ja adessiivi nagu muudes elusa agendiga passiivilausetes (näide 49).

(49) Mees oli võimuka proua Sigridi poolt täielikult ära hirmutatud.

\subsection{Imperatiiv}

Imperatiivi moodustamise võimalikkust on peetud üheks subjekti omadustest, selle põhjuseks on asjaolu, et imperatiivi saab moodustada vaid verbidest, mis eeldavad agentiivset subjekti: käskida ei saa seda, mille üle käsu adressaadil pole kontrolli (Sadock, Zwicky 1985: 172). Et imperatiivi saab kasutada ka mõningate mitteagentiivsete verbidega (nt Ole õnnelik!), ei osuta see kriteerium otseselt agentiivsetele verbidele, vaid pigem kontrolli puudumisele, s.t verbi mitteagentiivsusele (Verhoeven 2010: 223).

Ka eesti keeles eeldab imperatiivi kasutamine agentiivset tegijat. Mitteagentiivses konstruktsioonis on imperatiivi kasutamine võimatu või küsitav ka siis, kui (lausest välja jäetud) subjekt viitab inimesele (näited 50-51). Agentiivset konstruktsiooni võib aga käskivasse kõneviisi panna piiranguteta (näited 52-53). 
(50) *Huvita mind!

(51) * Ängista mind!

(52) Ehmata teda, küll ta siis vait jääb.

(53) Hirmuta neid natuke, siis lähevad ära.

Seega võib öelda, et agentiivses konstruktsioonis käitub stiimul tüüpilise (kanoonilise) subjektina, mis imperatiivis jäetakse väljendamata. Mitteagentiivses tundekausatiivikonstruktsioonis tal aga see omadus puudub.

\subsection{Sõnajärg}

Üks olulisemaid erijooni, mis eristab agentiivset ja tundekausatiivikonstruktsiooni, on sõnajärg: tüüpiliselt on tundekausatiivikonstruktsioonis kogejat väljendav objekt lause algul ja subjekt lause lõpul (OVS-sõnajärg), agentiivne konstruktsioon järgib aga tavalise transitiivlause sõnajärge (SVO). Sama on täheldatud ka soome keele puhul (Siiroinen 2001) ning see kehtib laiemaltki (vt Verhoeven 2010). Tundekausatiivikonstruktsiooni OVS-sõnajärje üks motivaatoreid on kahtlemata kogeja sobivus topikuks: kogejaks on enamasti inimene, samuti on kogejat väljendav sõna/fraas tüüpiliselt tuntud info.

Eesti keele sõnajärg liigub üha enam SVO suunas, s.t SVO-sõnajärge kasutatakse üha enam konstruktsioonides, kus varem kasutati muud sõnajärge (vt nt Lindström 2006). Ka tundeverbide kohta on väidetud, et kui on võimalik valida kahe konstruktsioonitüübi vahel, siis üha enam kaldutakse kasutama pigem sellist, kus kogeja markeeritakse subjektina (vrd näiteid 4 ja 5; Metslang 2006; 2007; Erelt, Metslang 2008). Sellega seoses võiks oletada ka SVO-sõnajärje sagenemist tundekausatiividega seoses. Samuti võib oletada, et agentiivses konstruktsioonis, mis on sarnasem tavalise transitiivse lausega kui TKK, on SVO-järjega lauseid oluliselt enam kui TKK-s. Nende hüpoteeside kontrollimiseks vaatlen lähemalt tundekausatiivikonstruktsiooni ja agentiivse konstruktsiooni sõnajärge.

Kõigepealt esitan vaadeldud verbide kohta üldandmed eesti kirjakeele korpuse 1990. aastate ilukirjanduse alamkorpuse põhjal, kus on kokku ligi 6 miljonit tekstisõna (vt http://www.cl.ut.ee/korpused/segakorpus/eesti_ilukirjandus_1990/). Osa neist verbidest esineb ainult tundekausatiivikonstruktsioonis (tabeli 1 I pool „Mitteagentiivsed verbid”), osa aga nii tundekausatiivi- kui ka agentiivses konsktruktsioonis (tabeli 1 II pool „Agentiiivsed verbid”). Konstruktsioone ei ole eristatud ning lihtsuse huvides on esitatud vaid subjekti (= stiimuli, tabelis $\mathrm{S}$ ) ja objekti (= kogeja, tabelis $\mathrm{O}$ ) vastastikune asend.

Ehkki verbide sagedus on korpuses väga erinev, võib mõningaid järeldusi siiski teha. Olulisim järeldus on, et agentiivsete verbidega domineerib SO-järg, nagu võiski arvata: 65 \% on SO-järjega (näide 54), 35 \% OS-järjega (näide 55). Seega soodustab agentiivse konstruktsiooni olemasolu SO-järje kasutamist.

(54) Või nagu see hull naine vaest Jane’i öösel ehmatas, mõtles ta nagu Marcelgi.

(55) Erikut ehmatas, et Liana ta vastu nii külm oli.

(56) Viimane teema huvitas mind rohkem.

(57) Mind huvitab teie arvamus. 
Tabel 1 .

SO- ja OS-järje sagedus eri verbidega

\begin{tabular}{lrrrrr} 
Verb & SO & OS & Kokku & SO (\%) & OS (\%) \\
& \multicolumn{7}{c}{ Mitteagentiivsed verbid (ainult } & TKK) \\
huvitama & 300 & 411 & 711 & $42 \%$ & $58 \%$ \\
vaimustama & 8 & 5 & 13 & $62 \%$ & $38 \%$ \\
hämmastama & 15 & 33 & 48 & $31 \%$ & $69 \%$ \\
rusuma & 5 & 2 & 7 & $71 \%$ & $29 \%$ \\
heidutama & 13 & 6 & 19 & $68 \%$ & $32 \%$ \\
kohutama & 32 & 13 & 45 & $71 \%$ & $29 \%$ \\
ängistama & 5 & 0 & 5 & $100 \%$ & $0 \%$ \\
Kokku & 378 & 470 & 848 & $45 \%$ & $55 \%$
\end{tabular}

Agentiivsed verbid (nii TKK kui ka AK)

$\begin{array}{lrrrrr}\text { ehmatama } & 53 & 18 & 71 & 75 \% & 25 \% \\ \text { hirmutama } & 57 & 15 & 72 & 79 \% & 21 \% \\ \text { üllatama } & 94 & 42 & 136 & 69 \% & 31 \% \\ \text { ärritama } & 63 & 26 & 89 & 71 \% & 29 \% \\ \text { häirima } & 147 & 126 & 273 & 54 \% & 46 \% \\ \text { Kokku } & 414 & 227 & 641 & 65 \% & 35 \%\end{array}$

Mitteagentiivsete verbidega (mis agentiivses konstruktsioonis ei osale) on OS-järje osakaal suurem: SO-järjega lauseid on kokku $45 \%$ (näide 56), OS-järjega $55 \%$ (näide 57).

Tabelist 1 näeme ka, et mõlema rühma sees on palju varieerumist nii verbide sageduse kui ka sõnajärje osas. Mitteagentiivsete verbide puhul mõjutab tulemust oluliselt verbi huvitama ja hämmastama suur sagedus ning OS-järje eelistamine, teisi verbe esineb tekstis üldse oluliselt vähem ning neid kasutatakse pigem SO-järjega. Seega võib tulemus muude verbide puhul olla ka mõnevõrra juhuslik. Võimalik on aga seegi, et iga verbi kasutamisel on mingi oma loogika: näiteks verbi kohutama puhul on sagedusandmed täpselt vastupidised kui verbil hämmastama, mida esines enam-vähem sama palju. Igal juhul näitab rühmasisene varieerumine, et TKK sõnajärg on väga varieeruv ning tõenäoliselt on käimas muutus SO-sõnajärje suunas.

Agentiivsete verbide puhul on varieeruvus väiksem. Teistest erineb rohkem häirima-verb, mis on väga sage ning mida kasutatakse enam-vähem võrdselt nii SO- kui OS-järjega (vastavalt $54 \%$ ja $46 \%$, näited 58-59).

(58) Ernie puudumine ei häirinud kedagi, moodustas ta ju tühise kuuendiku elektoraadist.

(59) Minnat häiris Roodina põikpäisus, kes teda mõista ei tahtnud. 
Häirima-verbi käitumist saab seletada asjaoluga, et agentiivset konstruktsiooni kasutatakse sellest verbist vähem: enamasti moodustatakse häiri$m a$-verbiga vaid tundekausatiivikonstruktsiooni (mida esindavad näited 58-59), agentiivset konstruktsiooni aga vaid 7 \% juhtudest (näide 60).

(60) Ta ei häirinud mind, lubades magada mul lõpuni kogu selle pika sügava une.

Võrdluseks: verbid hirmutama ja ehmatama, mida kasutatakse oluliselt enam SO-järjega (vt tabelit 2), esinevad ka oluliselt sagedamini agentiivses konstruktsioonis (hirmutama 39 \% kasutusjuhtumeist, ehmatama $37 \%$ ). Seega on agentiivse konstruktsiooni sageduse ja SO-sõnajärje sageduse vahel seos olemas.

Seda, et agentiivne konstruktsioon selgelt eelistab SO-sõnajärge, näeme aga tabelist 2 , kus on andmed verbide kohta, mis võivad esineda nii TKK-s kui agentiivses konstruktsioonis. Andmed on esitatud järgmiselt: tulp St esindab selget mitteagentiivset TKK konstruktsiooni, milles subjektiks on stiimul (vastab näitele 36), tulp Ag esindab agentiivset konstruktsiooni, milles subjekt on agent (vastab näitele 37), ning tulp St/Ag esindab nende vahepealset, milles on subjekti rollis inimesele (või elusolendile) viitav argument, ent selle tahtlik käitumine ei ole ilmne (näide 38).

Tabel 2 .

\section{Sõnajärg sõltuvalt stiimuli (subjekti) agentiivsusest}

\begin{tabular}{lccccccc} 
& \multicolumn{2}{c}{ St } & \multicolumn{2}{c}{ St/Ag } & \multicolumn{3}{c}{ Ag } \\
Verb & SO & OS & SO & OS & SO & OS & Kokku \\
ehmatama & 29 & 16 & 16 & 2 & 8 & 0 & 71 \\
hirmutama & 29 & 15 & 13 & 0 & 15 & 0 & 72 \\
üllatama & 62 & 40 & 15 & 2 & 17 & 0 & 136 \\
ärritama & 50 & 26 & 12 & 0 & 1 & 0 & 89 \\
häirima & 131 & 123 & 11 & 3 & 5 & 0 & 273 \\
Kokku & 301 & 220 & 67 & 7 & 46 & 0 & 641
\end{tabular}

Konkreetsest verbist sõltumata on SO-järg valdav, kui subjektiks on agent, ning sõnajärg on SO peaaegu alati ka siis, kui subjektiks on inimene, kelle tahtlikkus pole selge (tulp Ag ja St/Ag). Varieerumine on suur aga lausetes, kus subjektiks stiimul, seega puhtas tundekausatiivikonstruktsioonis.

Mida sellest kõigest järeldada? Eesti keele tundekausatiivikonstruktsioonis on toimumas sõnajärjemuutus, mille käigus üha enam eelistatakse OS-järje asemel kasutada SO-järge (nagu on valdav tavalises transitiivses lauses). Selle muutuse allikaks on predikaadid, mis võivad osaleda nii agentiivses kui ka mitteagentiivses tundekausatiivikonstruktsioonis: agentiivse konstruktsiooni sõnajärg on sarnane tavalise transitiivse lause sõnajärjega (SO), aga et konstruktsioonid on pealtnäha eristamatud, on see levinud ka sama predikaa- 
di mitteagentiivsesse konstruktsiooni. See omakorda on mõjutanud mitteagentiivset tundekausatiivikonstruktsiooni tervikuna: konstruktsiooni sees on varieeruvus suur. Kõige vähem on muutusest mõjutatud predikaadid, millel on vaid mitteagentiivne TKK (huvitama, hämmastama), ent ka nende puhul on sõnajärg tekstides varieeruv.

\section{Kokkuvõte}

Tundekausatiivikonstruktsioon on eesti keeles teinud läbi terve rea muutusi, milles põhjusi tuleb otsida eelkõige keelekontaktist.

Läänemeresoome keeltele on iseloomulik tundekausatiivikonstruktsioon, milles kogeja vormistatakse nagu tüüpiline objekt (partitiivis), stiimul aga nagu subjekt (nominatiivis), seejuures ei ole stiimul konstruktsioonis obligatoorne, s.t konstruktsiooni kasutatakse nii stiimulita kui ka stiimuliga. Kontaktkeelte mõjust tingituna on aga lõunapoolsemates läänemeresoome keeltes - eesti ja liivi keeles - muutunud stiimuli kasutamine konstruktsioonis obligatoorseks, samal ajal kui põhja- ja idapoolsemates keeltes on sama lausetüüp võimalik ka ilma stiimulita, s.t ilma grammatilise subjektita, predikaadi ainus argument on sel juhul objekt.

Stiimuli kinnistumisel lausestruktuuri võime oletada indoeuroopa, tõenäoliselt aga just naaberkeelte - läti ja vene keele - mõju, aga oma osa võib olla ka saksa keelel: on ju nii eesti, liivi kui ka läti keel olnud pikka aeg saksa keele mõjusfääris. Mis täpselt on muutuse allikaks, on raske välja selgitada, igal juhul on tegemist keelekontaktist tingitud nähtusega.

Stiimuli kinnistumine konstruktsiooni on omakorda peatanud kogeja grammatiseerumise subjektiks: kogejal on konstruktsioonis vähem subjekti käitumisomadusi kui ida- ja põhjapoolsetes läänemeresoome keeltes, eelkõige on marginaalseks muutunud samasuskustutus infiniitkonstruktsioonis. Sellegipoolest on eesti keeles tundekausatiivikonstruktsiooni objektil enam subjekti omadusi kui vastavates konstruktsioonides läti või vene keeles.

Stiimuli kinnistumise tagajärjel on tundekausatiivikonstruktsioon muutunud sarnase (ma)ks tavaliste transitiivlausetega. Paljude predikaatide puhul ongi olemas paralleelne agentiivne (transitiivne) konstruktsioon. Agentiivse ja mitteagentiivse konstruktsiooni erinevus püsib küll semantiliste rollide osas, ent formaalselt eristab neid ainult sõnajärg, mis näib samuti olevat haaratud muutustesse.

Agentiivsel ja mitteagentiivsel konstruktsioonil on aga erinevusi käitumisomaduste poolest: mitteagentiivset TKK-d ei saa näiteks kasutada impersonaalis, agentiivset konstruktsiooni saab. Passiivistamise käigus markeeritakse TKK-s stiimul elatiiviga, agentiivse konstruktsiooni puhul aga pigem kas adessiiviga või poolt-konstruktsiooniga. Mitteagentiivse TKK-ga ei saa (enamasti) kasutada ka imperatiivi: stiimuli rollis olev subjekt käitub selles osas nagu mittekanooniline subjekt. Agentiivse konstruktsiooni puhul on imperatiivi kasutamine tavaline.

Stiimuli kinnistumine lausestruktuuri ning agentiivse ja mitteagentiivse konstruktsiooni esinemine kõrvuti, isegi samade predikaatidega, on toonud kaasa ka sõnajärje muutuse. Kui TKK-le on iseloomulikum O(V)S-järg, siis agentiivne järgib üldiselt transitiivsele lausele omast $\mathrm{S}(\mathrm{V}) \mathrm{O}$-malli. Samade 
predikaatidega agentiivse konstruktsiooni ja TKK sõnajärje võrdlus näitab, et agentiivse konstruktsiooni olemasolu mõjutab ka sama predikaadiga TKK sõnajärge SVO-suunas. Tõenäoliselt just see muutus on kaasa toonud ka mitteagentiivse TKK sõnajärje suure varieeruvuse.

Eesti keele TKK puhul on tegu pikaajalise muutusteahelaga, mille on käivitanud kontaktid naaberkeeltega ning mille tulemusena on tundekausatiivikonstruktsioon sarnastunud ühelt poolt üha enam indoeuroopa keelte sama konstruktsioonitüübiga, teiselt poolt aga ka tavalise transitiivse lausega.

Uurimust on toetanud ETF-i grant $n r 7464$.

\section{Kasutatud lühendid}

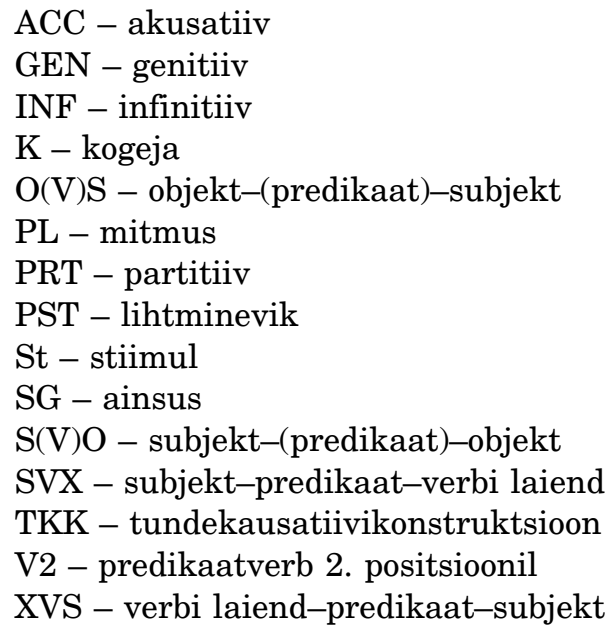

\section{Kirjandus}

Andrew s, Avery 1985. The Major Functions of the Noun Phrase. - Language Typology and Syntactic Description. Kd 1. Clause Structure. T. Shopen (toim). Cambridge: Cambridge University Press, lk 62-154.

B a r ðd a l, Jóhanna 2006. Construction-Specific Properties of Syntactic Subjects in Icelandic and German. - Cognitive Linguistics, nr 17, lk 39-106.

B i c k e l, Balthasar 2004. The Syntax of Experiencers in the Himalayas. - NonNominative Subjects. Kd 1. P. Bhaskararao, K. V. Subbarao (toim). Amsterdam-Philadelphia: Benjamins, lk 77-111.

B o s s o n g, Georg 1998. Le marquage de l'expérient dans les langues de l'Europe. - Actance et valence dans les langues de l'Europe. J. Feuillet (toim). Berlin: Mouton de Gruyter, lk 259-294.

Croft, William 1993. Case Marking and the Semantics of Mental Verbs. Semantics and the Lexicon. J. Pustejovsky (toim). Dordrecht: Kluwer Academic Publishers, lk 55-72.

EKK = Mati Erelt, Tiiu Erelt, Kristiina Ross, Eesti keele käsiraamat. 3., täiendatud trükk. Tallinn: Eesti Keele Sihtasutus, 2007. 
E r e lt, Mati 2004. Lauseliigendusprobleeme eesti grammatikas. - Lauseliikmeist eesti keeles. L. Lindström (toim). (Tartu Ülikooli eesti keele õppetooli preprindid 1.) Tartu: Tartu Ülikool, lk 7-15.

E relt, Mati, M ets lang, Helle 2006. Estonian Clause Patterns - from FinnoUgric to Standard Average European. - Linguistica Uralica, nr 4, lk 254-266.

E relt, Mati, M ets l ang, Helle 2008. Kogeja vormistamine eesti keeles: nihkeid SAE perifeerias. - Emakeele Seltsi aastaraamat 53 (2007). Tallinn: Teaduste Akadeemia Kirjastus, lk 9-22.

Givó n, Talmy 1997. Grammatical relations. Introduction. - Grammatical Relations. A Functionalist Perspective. T. Givón (toim). Amsterdam-Philadelphia: Benjamins, lk 1-84.

Haspelmath, Martin 2001. Non-Canonical Marking of Core Arguments in European Languages. - Non-Canonical Marking of Subjects and Objects. A. Y. Aikhenvald, R. M. W. Dixon, M. Onishi (toim). Amsterdam-Philadelphia: Benjamins, lk 53-83.

$\mathrm{H}$ a s p e $1 \mathrm{~m}$ a t h, Martin 2010. The Behaviour-before-Coding Principle in Syntactic Change. - Mélanges Denis Creissels. Franck Floricic (toim). Paris: Presses de L'École Normale Supérieure, lk 493-506.

H e i n s o o, Heinike 2010. Mā ja pūd levë̈d, meid eb les. The Subject and the Predicate in Votic. (Linguistica Uralica Supplementary Series / Vol. 4.) Tallinn: Teaduste Akadeemia Kirjastus.

ISK = Auli Hakulinen, Maria Vilkuna, Riitta Korhonen, Vesa Koivisto, Tarja Riitta Heinonen, Irja Alho, Iso suomen kielioppi. (Suomalaisen Kirjallisuuden Seuran toimituksia 950.) Helsinki: Suomalaisen Kirjallisuuden Seura, 2004.

Ke e n a n, Edward L. 1976. Towards a Universal Definition of „subject”. - Subject and Topic. Charles N. Li (toim). New York: Academic Press, lk 303-333.

K o k s, Helen 2004. Subjekti ja objekti käitumisreeglid komplekslauses. - Lauseliikmeist eesti keeles. L. Lindström (toim). (Tartu Ülikooli eesti keele õppetooli preprindid 1.) Tartu: Tartu Ülikool, lk 34-39.

Li n d strö m, Liina 2002. Veel kord subjekti ja predikaadi vastastikusest asendist laiendi järel. - Emakeele Seltsi aastaraamat 47. Tartu: Emakeele Selts, lk 87-105.

L i n d s t r ö m, Liina 2006. Infostruktuuri osast eesti keele sõnajärje muutumisel. - Keel ja Kirjandus, nr 11, lk 875-888.

L i n d s t r ö m, Liina, Tr a g e l, Ilona 2007. Eesti keele impersonaali ja seisundipassiivi vahekorrast adessiivargumendi kasutamise põhjal. - Keel ja Kirjandus, nr 7, lk 532-553.

Mets lang, Helle 2006. Predikaat ajastut kogemas. - Keel ja Kirjandus, nr 9, lk 714-727.

M e t s l a n g, Helle 2007. Predicates in Estonian Sentences. Contact-Induced Developments? - Combat pour les langues du monde. - Fighting for the World's Languages, Hommage à Claude Hagège. M. M. J. Fernandez-Vest (toim). Paris: L'Harmattan, lk 363-375.

M u st, Mari 1987. Kirderannikumurre. Häälikuline ja grammatiline ülevaade. Tallinn: Valgus.

O n is h i, Masayuki 2001. Non-Canonically Marked Subjects and Objects. Parameters and Properties. - Non-Canonical Marking of Subjects and Objects. A. Y. Aikhenvald, R. M. W. Dixon, M. Onishi (toim). Amsterdam-Philadelphia: Benjamins, lk 1-51. 
P a l m e r, Frank Robert 1994. Grammatical Roles and Relations. Cambridge: Cambridge University Press.

Pihlak, Ants 1993. A Comparative Study of Voice in Estonian. (Eesti Sisekaitse Akadeemia toimetised.) Tallinn.

P ör n, Michaela 2008. Psychophysical and Physical Causative Emotion Verbs in Finnish. The Temporal Structure of Causative Emotion Verb + Infinitive 1 Constructions within Conceptual Semantics. - SKY Journal of Linguistics, nr 21, lk 201-218.

R a j a n d i, Henno 1999 [1968]. Eesti impersonaali ja passiivi süntaks. (Eesti Keele Instituudi toimetised 3.) Tallinn: Eesti Keele Instituut.

S a d o c k, Jerrold M., Z w i c k y, Arnold M. 1985. Speech Act Distinction in Syntax. - Language Typology and Syntactic Description. T. Shopen (toim). Kd 1. Cambridge: Cambridge University Press, lk 155-196.

S a h k a i, Heete 2011. Eesti keele genitiivse agendifraasi süntaks. - Keel ja Kirjandus, nr 1, lk 12-30.

S a n d s, Kristina, C a m p b e 11, Lyle 2001. Non-Canonical Subjects and Objects in Finnish. - Non-Canonical Marking of Subjects and Objects. A. Y. Aikhenvald, R. M. W. Dixon, M. Onishi (toim). Amsterdam-Philadelphia: Benjamins, lk 251-305.

S i i r o i n e n, Mari 2001. Kuka pelkää, ketä pelottaa. Nykysuomen tunneverbien kielioppia ja semantiikkaa. (Suomalaisen Kirjallisuuden Seuran toimituksia 844.) Helsinki: Suomalaisen Kirjallisuuden Seura.

$\mathrm{Z}$ a i t s e v a, Maria 2001. Vepsän kielen lauseoppia. (Suomalais-ugrilaisen Seuran toimituksia 241.) Helsinki: Suomalais-ugrilainen Seura.

T a e 1, Kaja 1988. Sõnajärjemallid eesti keeles (võrrelduna soome keelega). (Preprint KKI-56.) Tallinn: Eesti NSV Teaduste Akadeemia Keele ja Kirjanduse Instituut.

Tolu k, Ivi 2002. Eesti keele tundeverbid. (Käsikirjaline bakalaureusetöö Tartu Ülikooli eesti keele osakonnas.)

Torn, Reeli 2006. poolt-tarind eesti keele impersonaalis ja passiivis. - Lause argumentstruktuur. Pille Penjam (toim). (Tartu Ülikooli eesti keele õppetooli preprindid 2.) Tartu: Tartu Ülikooli eesti keele õppetool, lk 108-121.

U u s p õ ld, Ellen 1970. On the Agent Adverbial in the tud-Construction. Generatiivse grammatika grupi aastakoosolek. Teesid. Tartu: Tartu Riiklik Ülikool, lk $38-43$.

Ver hoeven, Elisabeth 2010. Agentivity and Stativity in Experiencer Verbs. Implications for a Typology of Verb Classes. - Linguistic Typology, nr 14, lk 213251.

Vi it s o, Tiit-Rein, Liivi keele sõnaraamat (käsikiri). 


\section{Causative Emotion Construction in Estonian}

Keywords: experiencer constructions, causative emotion verbs, word order, syntax, Estonian

The Causative Emotion Construction (CEC) is one of the constructions for expressing experiential events in Estonian. In a CEC, the experiencer is marked as an object and the stimulus as a subject. In this paper, the CEC is examined in respect of the occurrence of the stimulus, a subject's behavioural properties of the object argument (semantically: experiencer) and the effect of the agentivity of the subject argument (semantically: stimulus). The data are compared with those of Latvian and Russian as contact languages, and with those of the other Finnic languages.

The Estonian CEC deviates from the respective constructions used in other Finnic languages in the obligatoriness of the stimulus argument, i.e. unlike in the rest of the Finnic languages, in Estonian the stimulus is an obligatory part of the construction, acting in this respect more similarily to its Latvian and Russian counterparts. Also, the same tendencies are revealed in the behavioural properties of the experiencer argument.

The second part of the paper investigates the effects of the agentivity of the stimulus argument: a proper CEC (with a non-agentive, inanimate stimulus) has many restrictions that do not apply to an agentive stimulus. These restrictions concern the use of the impersonal voice, the case of the agent argument in the passive (only the elative can be used in the CEC), the use of the imperative, and word order. More attention is paid to word order, which has a notable variation: with a non-agentive stimulus, the word order is more often OVS (yet, with remarkable variation depending on the verb), whereas with the agentive stimulus the word order is mostly SVO.

Liina Lindström (b. 1973), PhD, University of Tartu, Department of Estonian and General Linguistics, senior researcher, liina.lindstrom@ut.ee 